\title{
Multidisciplinary approach between physicians and physiotherapists in urogynecology: how can we make it stronger?
}

\author{
Glaucia Miranda Varella Pereira $^{1} \cdot$ Patricia Driusso $^{2} \cdot$ Cristine Homsi Jorge Ferreira $^{3} \cdot$ Luiz Gustavo Oliveira Brito $^{1}$
}

Received: 17 May 2020 / Accepted: 28 May 2020 / Published online: 17 July 2020

(C) The International Urogynecological Association 2020

Within the field of urogynecology, most societies have written guidelines recommending patient treatment with the assistance of more than one healthcare professional [1-3]. There are studies showing that the communication between healthcare professionals and the knowledge of each other's roles and definitions are key factors that lead to a successful team and optimal patient outcomes [4]. Urogynecology is a field with a well-established role for physiotherapists; however, the term physiotherapy is often mistakenly used by physicians and other health professionals to be synonymous with physiotherapeutic resources or conservative treatment [5]. Physiotherapy is defined as services provided by physiotherapists to individuals and populations that seek to develop, maintain, and restore maximum movement and functional ability throughout the lifespan [6]. The work of the physiotherapist focused in urogynecology originated within a broader role in women's health physiotherapy [7]. Women's health physiotherapists provide health promotion, prevention, and rehabilitation, not only in urogynecology but also in breast diseases and obstetrics, being active throughout the woman's life cycle. Moreover, pelvic floor physiotherapy is a term used to designate the physiotherapy work focused on the pelvic floor issues of children, men or women. Despite the amount of evidence-based literature demonstrating the role of physiotherapy in this area, randomized controlled trials (RCT) on costeffectiveness and studies on the barriers and facilitators for the teamwork of physicians and physiotherapists in urogynecology are scarce.

Luiz Gustavo Oliveira Brito

lgobrito@unicamp.br

1 Department of Obstetrics and Gynecology, School of Medical Sciences, University of Campinas, Rua Alexander Fleming 101, Cidade Universitária, Campinas, SP 13083-881, Brazil

2 Department of Physiotherapy, Federal University of São Carlos, São Carlos, Brazil

3 Department of Health Sciences, Ribeirão Preto Medical School, University of São Paulo, São Paulo, Brazil
Recent retrospective studies have revealed the importance of collaborative action between urogynecology and physical therapy in the treatment of female pelvic pain $[8,9]$. When addressing pelvic pain and female sexual dysfunction, physiotherapists can contribute to assessing and treating such women with the multidisciplinary approach, and clinical and scientific research indicate its efficacy and safety [10]. Concerning female urinary incontinence, there is evidence to support recommendations that pelvic floor muscle training (PFMT) should be routinely implemented as first-line treatment [11]. Multidisciplinary management of fecal incontinence has also been encouraged [12].

The International Continence Society Consensus in 2014 joined 17 experts in a multidisciplinary meeting involving the specialties physiotherapy, medicine (urology and general practice), nursing, patient education, psychology, and statistics. They pointed out the importance of educational institutions in raising clinicians' awareness of the behavior change in pelvic floor muscle training, the assessment and employment of patient-focused adherence strategies, as well as the provision of accurate information to develop patients' knowledge and confidence by correcting pelvic floor contraction, promoting positive PFMT role models and prioritizing training in daily life [13].

Thus, it seems that there is growing evidence that a singlespecialty approach to treating patients with complex symptoms and pathological condtions affecting the pelvic floor is becoming less than ideal. This model has been associated with failure in rates of surgeries, resolution of symptoms, and poor outcomes [14]. Moreover, some of the components of this multidisciplinary team may not have the same perception of their roles. Data from an old study (1980) suggested that physiotherapists wished to have their bond strengthened [15]. Another study (1992) found that only $17 \%$ of physiotherapists reported that physicians had a satisfactory knowledge and understanding of their profession [16]. Therefore, newer data on this subject are urgently needed. A respectful and understanding relationship between professionals is vital to building 
an efficient multidisciplinary team. Consensus can be reached by such a team and complex cases can frequently be revisited throughout the continuity of care [17]. Various professionals working collaboratively with their skills of expertise would be essential for facing multiple pelvic floor symptoms in urogynecology with a broad view of women's specificities and health problems [18]. Let us work together to strengthen our bonds and, most importantly, to improve care for our patients!

\section{Compliance with ethical standards}

\section{Conflicts of interest None.}

\section{References}

1. NICE. NICE guidance - urinary incontinence and pelvic organ prolapse in women: management. BJU Int. 2019;123(5):777-803.

2. ACOG. Female Sexual Dysfunction. ACOG practice bulletin clinical management guidelines for obstetrician-gynecologists, number 213. Obstet Gynecol. 2019;134(1):e1-e18.

3. Fall M, Baranowski AP, Fowler CJ, et al. EAU guidelines on chronic pelvic pain. Eur Urol. 2010;57(1):35-48.

4. O'Reilly P, Lee SH, O'Sullivan M, Cullen W, Kennedy C, MacFarlane A. Assessing the facilitators and barriers of interdisciplinary team working in primary care using normalisation process theory: an integrative review. PLoS One. 2017;12(5):e0177026.

5. Bo K, Frawley HC, Haylen BT, et al. An International Urogynecological Association (IUGA)/International Continence Society (ICS) joint report on the terminology for the conservative and nonpharmacological management of female pelvic floor dysfunction. Int Urogynecol J. 2017;28(2):191-213.

6. World Confederation for Physical Therapy. Position Statement. Accessed at https://www.wcpt.org/sites/wcpt.org/files/files/ WCPT_Description_of_Physical_Therapy-Sep07-Rev_2.pdf. Accessed on 16 May 2020.
7. The International Organization of Physical Therapists in Pelvic and Women's Health. IOPTPWH newsletter, March 2020, 1-19. https://www.wcpt.org/ioptwh/newsletters.

8. Lillemon JN, Nardos R, Kaul MP, Johnson AN, Choate A, Clark AL. Complex female pelvic pain: a case series from a multidisciplinary clinic in urogynecology and physiatry. Female Pelvic Med Reconstr Surg. 2019;25(2):e34-9.

9. Brown HW, Barnes HC, Lim A, Giles DL, McAchran SE. Better together: multidisciplinary approach improves adherence to pelvic floor physical therapy. Int Urogynecol J. 2020;31(5):887-93.

10. Berghmans B. Physiotherapy for pelvic pain and female sexual dysfunction: an untapped resource. Int Urogynecol J. 2018;29(5): 631-8.

11. Abrams P, Andersson KE, Apostolidis A, et al. 6th International Consultation on Incontinence. Recommendations of the International Scientific Committee: evaluation and treatment of urinary incontinence, pelvic organ prolapse and faecal incontinence. Neurourol Urodyn. 2018;37(7):2271-2.

12. O'Leary BD, Agnew GJ, Fitzpatrick M, Hanly AM. Patient satisfaction with a multidisciplinary colorectal and urogynaecology service. Ir J Med Sci. 2019;188(4):1275-8.

13. Dumoulin C, Hay-Smith J, Frawley H, McClurg D, Alwijnse D, Bo $\mathrm{K}$, et al. Consensus statement on improving pelvic floor muscle training adherence: International Continence Society 2011 stateof-the-science seminar. Neurourol Urodyn. 2014;34(7):600-5.

14. Pandeva I, Biers S, Pradhan A, Verma V, Slack M, Thiruchelvam $\mathrm{N}$. The impact of pelvic floor multidisciplinary team on patient management: the experience of a tertiary unit. J Multidiscip Healthc. 2019;12:205-10.

15. Ross CA, Roberts LW, Olson L. The doctor-physiotherapist relationship: the physiotherapists' perspective. Physiother Can. 1980;32(4):219-23.

16. Kenny D, Adamson B. Medicine and the health professions: issues of dominance, autonomy and authority. Aust Health Rev. 1992;15(3):319-34.

17. Taddei TH. A multidisciplinary approach: group dynamics. J Clin Gastroenterol. 2013;47(Suppl):S27-9.

18. Gopinath D, Jha S. Multidisciplinary team meetings in urogynaecology. Int Urogynecol J. 2015;26(8):1221-7.

Publisher's note Springer Nature remains neutral with regard to jurisdictional claims in published maps and institutional affiliations. 